\title{
A frailty index predicts survival and incident multimorbidity independent of markers of HIV disease severity
}

\author{
Giovanni Guaraldi ${ }^{a}$, Thomas D. Brothers ${ }^{b}$, Stefano Zona ${ }^{a}$, \\ Chiara Stentarelli ${ }^{a}$, Federica Carli ${ }^{a}$, Andrea Malagoli ${ }^{a}$, \\ Antonella Santoro ${ }^{a}$, Marianna Menozzi ${ }^{a}$, Chiara Mussi ${ }^{c}$, \\ Cristina Mussini ${ }^{a}$, Susan Kirkland ${ }^{\mathbf{d}}$, Julian Falutz ${ }^{\mathbf{e}}$ \\ and Kenneth Rockwood ${ }^{\mathrm{f}}$
}

\begin{abstract}
Objectives: Aging with HIV is associated with multisystem vulnerability that might be well characterized by frailty. We sought to construct a frailty index based on health deficit accumulation in a large HIV clinical cohort and evaluate its validity including the ability to predict mortality and incident multimorbidity.

Design and methods: This is an analysis of data from the prospective Modena HIV Metabolic Clinic cohort, 2004-2014. Routine health variables were screened for potential inclusion in a frailty index. Content, construct, and criterion validity of the frailty index were assessed. Multivariable regression models were built to investigate the ability of the frailty index to predict survival and incident multimorbidity (at least two chronic disease diagnoses) after adjusting for known HIV-related and behavioral factors.
\end{abstract}

Results: Two thousand, seven hundred and twenty participants (mean age $46 \pm 8 ; 32 \%$ women) provided 9784 study visits; 37 non-HIV-related variables were included in a frailty index. The frailty index exhibited expected characteristics and met validation criteria. Predictors of survival were frailty index $(0.1$ increment, adjusted hazard ratio $1.63,95 \%$ confidence interval $1.05-2.52)$, current $C D 4^{+}$cell count $(0.48,0.32-0.72)$, and injection drug use $(2.51,1.16-5.44)$. Predictors of incident multimorbidity were frailty index (adjusted incident rate ratio 1.98, 1.65-2.36), age (1.07, 1.05-1.09), female sex $(0.61,0.40-0.91)$, and current $C D 4^{+}$cell count $(0.71,0.59-0.85)$.

Conclusion: Among people aging with HIV in northern Italy, a frailty index based on deficit accumulation predicted survival and incident multimorbidity independently of HIV-related and behavioral risk factors. The frailty index holds potential value in quantifying vulnerability among people aging with HIV.

Copyright $\odot 2015$ Wolters Kluwer Health, Inc. All rights reserved.

AIDS 2015, 29:1633-1641

Keywords: aging, frail elderly, frailty, HIV, multimorbidity, survival

\footnotetext{
${ }^{a}$ Department of Medical and Surgical Sciences for Adults and Children, Clinic of Infectious Diseases, University of Modena and Reggio Emilia, Modena, Italy, ${ }^{b}$ Faculty of Medicine, Dalhousie University, Halifax, Nova Scotia, Canada, ${ }^{\mathrm{C}}$ Department of Biomedical, Metabolic and Neural Sciences, University of Modena and Reggio Emilia, Modena, Italy, ${ }^{\mathrm{d}}$ Department of Community Health and Epidemiology, Dalhousie University, Halifax, Nova Scotia, ${ }^{\mathrm{e}}$ Chronic Viral Illness Service, McGill University Hospital Center, Montreal, Quebec, and 'Department of Medicine (Geriatric Medicine and Neurology), Dalhousie University, Halifax, Nova Scotia, Canada.

Correspondence to Giovanni Guaraldi, MD, Clinica delle Malattie Infettive, Largo del Pozzo 71, Modena 41100, Italy.

E-mail: giovanni.guaraldi@unimore.it
}

Received: 23 March 2015; revised: 16 April 2015; accepted: 22 May 2015.

DOI:10.1097/QAD.0000000000000753

ISSN 0269-9370 Copyright () 2015 Wolters Kluwer Health, Inc. All rights reserved. Copyright @ 2015 Wolters Kluwer Health, Inc. All rights reserved. 


\section{Introduction}

Aging with HIV increases risk for many age-related health problems - the so-called HIV-associated nonAIDS conditions, including cardiovascular disease, osteoporosis, chronic obstructive pulmonary disease, and non-AIDS cancers - which span multiple physiologic systems and causes [1-4]. People who develop one of these conditions are more likely to accumulate further health problems. Multimorbidity contributes to further vulnerability and complexity in clinical management in the contemporary antiretroviral therapy era $[3,5-7]$.

Interest is strong in methods to identify individuals at risk of multimorbidity and other adverse health outcomes, in addition to mortality. In geriatric medicine, such multisystem vulnerability is quantified using the construct of frailty, which is a state of increased vulnerability related to the degradation of homeostatic mechanisms [8]. Although often linked to old age, frailty can be described across the life course including among individuals with acquired vulnerability states [9-11].

Two different conceptual models inform frailty measurement [8]. One approach uses rules-based tools to measure frailty, wherein specific criteria must be met in order for a person to be identified as frail. The most common application of this approach describes frailty as a clinical phenotype composed of at least three of five specific, ageassociated health deficits: physical shrinking, diminished strength, reduced exercise tolerance, slowness, and reduced activity [12]. Many other rules-based frailty measurement scales have been introduced, including other specific criteria such as cognitive impairment or polypharmacy [13-15]. In the context of HIV, the Veterans Aging Cohort Study (VACS) index, which sums weighted measures of chronological age, current $\mathrm{CD} 4^{+}$ T-cell count, HIV viral load, hemoglobin, liver fibrosis, kidney function, and hepatitis $\mathrm{C}$ virus coinfection, has been proposed as a rules-based measure of frailty [16].

Another approach describes frailty as the cumulative effects of general health deficits that are more likely to be acquired with age [17]. The proportion of deficits an individual has acquired out of a group of at least 30 health variables, known as a frailty index, indicates frailty severity. The frailty index approach enables grading across a continuum of vulnerability (from fittest to frailest) and more sensitively grades risk of adverse outcomes than rules-based approaches $[14,18]$. A frailty index can be calculated from diverse groups of health variables, including existing or routinely collected health information [19]. Although employed successfully in other areas $[8,20,21]$, the utility of the frailty index in identifying vulnerability among people aging with HIV is unknown $[22,23]$.

In the present study, we sought to construct a frailty index from health variables collected as part of assessments in an
HIV clinic. We assessed the validity of the frailty index, described the characteristics of frailty in a large clinical cohort, and evaluated the ability of a frailty index to predict mortality and incident multimorbidity.

\section{Methods}

\section{Setting and sample}

This is an analysis of data from the prospective Modena HIV Metabolic Clinic (MHMC) cohort. The multidisciplinary metabolic clinic at the University of Modena and Reggio Emilia School of Medicine in Modena, Italy, was initiated in 2003/2004 to comprehensively assess longitudinal metabolic changes among people with HIV [1,24]. We included visits from June 2003 to July 2014. The data included in the cohort study are those used in the clinical care of participants, including disease diagnoses and vital statistics.

\section{Frailty index}

A frailty index calculates the proportion of health deficits individuals have accumulated out of a group of relatively nonspecific health variables. Health variables, including signs and symptoms of disease, laboratory measures, and self-reported data, can be included in a frailty index if they meet some basic criteria: they should characterize acquired health deficits that are generally age-related and, as a group, must cover a range of physiologic systems [20]. Although certain deficits might have small effects on their own, their cumulative effects can be large. If at least around 30 variables are included, the number of deficits appears to be much more informative than the specific nature of the deficits $[20,25,26]$. As such, different health variables and numbers of variables can be used in different frailty indices, including information that is already being gathered in clinical care $[19,27,28]$. Because frailty indices grade a continuum of vulnerability, from fittest to frailest, they can be used to predict many different adverse outcomes including death, institutionalization, falls, and specific conditions such as heart disease [29] and dementia [30].

Health measurements collected as part of regular clinic assessments were screened for inclusion in the frailty index. We selected health variables that were not representative of HIV viral replication or immune deficiency. As we intended to assess the ability of a frailty index to predict incident multimorbidity as well as survival, we also excluded from the frailty index variables used to define our multimorbidity outcome (described in the next section). Although we selected one group of variables, other frailty indices need not be made up of these variables. We also identified health deficits through cutoffs used in the MHMC setting. Variables in other frailty indices could use other cutoffs, depending on what is recognized as a health deficit in that setting.

Each variable included in the frailty index was recorded with values of one when a deficit was present and zero 
when absent [20]. Missing values were removed from both the numerator and the denominator of the frailty index, and observations were included if they had at least $80 \%$ of available health variables at that visit [14].

\section{Validation strategy}

We evaluated the validity of the frailty index using a threepart approach, assessing content, construct, and criterion validity [31]. Content validity is assayed by whether the approach being used is sensible to experts in the field (or 'sensible on its face'). In this case, included health variables were all among those routinely collected through assessments at an HIV clinic. To assess construct validity, we compared characteristics of this frailty index to those consistently demonstrated by frailty indices in HIVnegative cohorts $[15,20,25]$. These include the relationship between frailty index score and age (on a log scale, around $1 \%$ in clinical or institutional samples); distribution of frailty index scores (usually Gaussian in clinical samples); and the existence of a submaximal limit to frailty, for example, $99 \%$ of people have frailty indices less than $0.7[15,20]$. Among people with frailty index scores closer to this upper limit, the relationship between frailty and increasing age attenuates and approaches zero, as people die rather than accumulate more deficits [32]. We also evaluated associations between frailty index scores and other measures of HIV-related vulnerability: current and nadir $\mathrm{CD} 4^{+}$cell count, HIV viral load, and VACS index score [16,33-35]. As per protocol, VACS index scores were available for those participants with nonmissing values for all included variables. To test criterion validity, we evaluated the ability of the frailty index to independently predict two clinically meaningful outcomes in this setting: mortality and incident multimorbidity.

\section{Outcomes}

Vital status is regularly updated in MHMC via telephone contact and hospital records. We defined multimorbidity as the presence of two or more of the following eight health problems: cardiovascular disease (clinical diagnosis with history of myocardial infarction, stroke, revascularization, or peripheral artery disease); hypertension (blood pressure measured twice $\geq 140 \mathrm{mmHg}$ systolic or $\geq 90 \mathrm{mmHg}$ diastolic or taking antihypertensive medicine); diabetes mellitus type two (measured fasting glucose $\geq 126$ or oral glucose tolerance test $>200$ or on treatment); chronic kidney disease (estimated glomerular filtration rate $<60 \mathrm{ml} / \mathrm{min}$, via Modification of Diet in Renal Disease study equation [36]); cirrhosis (fibrosis-4 score >3.25 [37]); chronic obstructive pulmonary disease (forced expiratory volume in one second/forced vital capacity ratio $<0.7)$; osteoporosis (dual-energy X-ray absorptiometry $T$ or $Z$ score $<-2.5$ or fragility fracture); or any cancer (clinical diagnosis with biopsy confirmation). We included multimorbidity as an outcome as it has been identified as a meaningful health state among people living with HIV $[5,6]$, and because mortality in this cohort was expected to be relatively low [38].

\section{Covariates}

Age was recorded at each study visit and sex at baseline. Current and nadir $\mathrm{CD}^{+}$cell counts and HIV viral load measurements were treated as continuous variables for correlation analyses, and when included in regression models, they were grouped into clinically relevant categories. CD $4^{+}$ cell count was divided into four groups $(<100,101-350$, $351-500$, and $>500$ cells $/ \mu \mathrm{l})$. HIV viral load was categorized as detectable or undetectable ( $\leq 40$ copies $/ \mathrm{ml})$. Smoking history was assessed at each study visit; pack-years were calculated and grouped into 10-year intervals. History of injection drug use was assessed at baseline.

\section{Analysis}

Descriptive statistics and frailty index scores at first visit were calculated and distributions visualized. Crosssectional relationships between log-frailty index scores and years of age were evaluated by linear regression $[20,25]$. To identify potential attenuation in the relationship of frailty and increasing age among frailer participants, we also performed regressions on age among participants with frailty index scores in the top 50th, 85th, and 95th percentiles. Pearson correlation coefficients assessed crosssectional associations between frailty index and other continuous health measures. For prediction models, frailty index scores were categorized into 0.1 increments. Each covariate was first evaluated in univariate prediction models, and covariates significantly associated with the outcome were then combined in multivariable models. Cox regression models were used to assess survival and hazard ratios with 95\% confidence intervals (CIs) were calculated. Incident multimorbidity prediction analysis included participants without multimorbidity at baseline. We used longitudinal generalized estimating equation models for panel data and calculated incident rate ratios with 95\% CIs. Censoring occurred at the study visit when incident multimorbidity was first diagnosed, or at most recent visit.

In further exploratory analyses, we modified the original frailty index to create two additional frailty indices: one with the eight comorbidity variables added, and another with comorbidity and HIV severity and also immune deficiency markers added. We then compared the ability of these frailty indices to classify risk for 2 and 5-year mortality using receiver-operating characteristic (ROC) curves, by calculating the area under the curve with 95\% CIs. We also compared the predictive ability of the VACS index. Statistical significance was set a $P$ less than 0.05 , and data were analyzed using SPSS 21.0.0 (IBM Corp., Armonk, New York, USA).

\section{Ethics}

Approval for the MHMC cohort was obtained from the Research Ethics Board of the University of Modena and 
Reggio Emilia, and all participants provided written consent.

\section{Results}

Following established criteria, 37 variables were selected for inclusion in a frailty index (Table 1); 2722 participants in the MHMC cohort provided 9784 study visits with available frailty index scores $(72 \%$ of all MHMC study visits). Participants were generally middle aged and most were male with undetectable HIV viral load and CD4 ${ }^{+}$ cell counts above 500 cells/ $\mu 1$ (median 557, interquartile range $400-726$ cells $/ \mu$; ; Table 2 ).

Frailty index scores at first visit ranged from 0.00 to 0.63 (mean $0.31 \pm 0.10$; median 0.30 ) and were normally distributed. Frailty index scores increased exponentially with age. On a log scale, frailty index scores increased by $1.8 \%(2 / 3$ of one deficit) with each year of age $(P<0.001)$. Frailty index scores increased $0.4 \%$ with each year of age $(P<0.001)$ among patients with frailty index at or above the sample mean; $0.1 \%$ among participants with frailty index scores in the top 85th percentile $(\geq 0.42, P=0.1)$, and $0.1 \%$ among participants in the 95th percentile $(\geq 0.48,0.1 \%, P=0.2)$. Frailty index scores at first visit were modestly correlated with nadir $\mathrm{CD} 4{ }^{+}$cell count $(r=-0.15, P<0.001)$ and VACS index $(r=0.34, P<0.001)$, but not with current $\mathrm{CD} 4^{+}$ cell count $(r=-0.04, P=0.07)$ or HIV viral load $(r=-0.02, P=0.5)$.

There were 34 deaths in the sample over 8206 person-years follow-up (0.41/100 person-years follow-up). In univariate analyses, significant predictors of survival were frailty index (hazard ratio 2.32, 95\% CI 1.53-3.52), age $(1.05,1.00-1.09)$, current $\mathrm{CD} 4^{+}$cell count $(0.37,0.24-$ $0.54)$, nadir $\mathrm{CD}^{+}$cell count $(0.42,0.24-0.75)$, and injection drug use $(3.56,1.81-7.01)$. When these were combined in a multivariate model, frailty index, current $\mathrm{CD}^{+}{ }^{+}$cell count, and injection drug use remained significant (Fig. 1).

Most $(88 \%, n=2383)$ of participants did not have multimorbidity at baseline. Of these, 232 (9.7\%) acquired multimorbidity during follow-up. In univariate analysis, frailty index score (incident rate ratio $2.34,1.98-2.76$ ), age $(1.09,1.07-1.11)$, female sex $(0.41,0.27-0.61)$, current $\mathrm{CD}^{+}$cell count $(0.65,0.54-0.78)$, pack-years smoking $(1.20,1.09-1.31)$, and IDU $(1.47,1.07-2.02)$ were each predictive of incident multimorbidity. When these factors were combined in multivariate analysis, frailty index score, age, sex, and current $\mathrm{CD} 4{ }^{+}$cell count remained significant (Fig. 2).

We then compared the ability of three frailty indices to classify mortality risk: the 37-item frailty index, a frailty index with the eight comorbidity variables added (45 items total), and a frailty index with both these and eight HIV-related variables added (53 items total). Among participants included in the study, $100 \%$ of whom had nonmissing 37-item frailty index scores at baseline, $58 \%$ had nonmissing 45 -item frailty index scores, $81 \%$ had nonmissing 53 -item frailty index scores, and $40 \%$ had nonmissing VACS index scores. Area under the ROC increased with more items in the frailty index, but these differences were not significant (Table 3 ). The VACS index exhibited better discriminatory ability for 2-year mortality than the 37-item frailty index, but not the other frailty indices. The VACS index did not differ from any frailty index in prediction of 5-year mortality.

\section{Discussion}

In a large, well characterized cohort of HIV-positive men and women in northern Italy, we assessed frailty by constructing a frailty index from routinely collected health variables that were not measures of immune deficiency or HIV viral replication. We found that the frailty index exhibited expected characteristics and was able to predict survival and incident multimorbidity independent of age, behavioral, and HIV-related variables. We further found that frailty indices with added variables, including HIV-related variables, discriminated mortality risk similarly to the frailty indices without these variables. The frailty indices, which were composed of many general health deficits, performed similarly to the VACS index in their ability to discriminate mortality risk.

Our results should be interpreted with caution. There were relatively few endpoints during follow-up, which could have affected our estimates from regression models. However, this potential lack of statistical power increased our risk of type II error, and so did not influence the direction of our findings that frailty was a significant predictor of both survival and multimorbidity. Parameter estimates were also generally stable between univariate and multivariate analyses. Although further follow-up is needed to capture more data related to mortality, the low mortality rate reflects increased life expectancy with HIV [38]. As such, it will be important to evaluate relationships between frailty and risk for other clinically meaningful outcomes, including geriatric syndromes, mobility limitations, falls, quality of life, and cognitive impairment $[23,30,43]$. Applying this approach in other cohorts with mortality data could also help advance understanding of the relationship between frailty and mortality risk in people aging with HIV. Although evidence of the validity of the frailty index as constructed here is encouraging, the frailty index approach should also be cross-validated in other HIV-positive cohorts using different variables in different settings. These questions are motivating active inquiry by our group.

A recent review summarized what is known about frailty in people aging with HIV [22]. Previous studies of frailty in people with HIV have applied phenotypic frailty scales, 
Table 1. Health variables included in the frailty indices and description of deficit scoring.

\begin{tabular}{|c|c|c|}
\hline No. & Variable & Deficit description \\
\hline \multicolumn{3}{|c|}{ 37-item frailty index } \\
\hline 1 & Lipoatrophy & Multicenter AIDS Cohort Study (MACS) criteria [39] \\
\hline 2 & Lipohypertrophy & MACS criteria [40] \\
\hline 3 & Nonalcoholic fatty liver disease & Liver/spleen ratio $<1.1$ \\
\hline 4 & Menopause or male hypogonadism & $\begin{array}{l}\text { If female: } \mathrm{FSH}>30 \mathrm{IU} / \mathrm{l} \text { and } \mathrm{LH}<30 \mathrm{IU} / \mathrm{I} \text { and/or absence } \\
\text { of menstruation }>1 \text { year } \\
\text { If male: testosterone }<300 \mathrm{ng} / \mathrm{dl}\end{array}$ \\
\hline 5 & High or low BMI & $<18$ or $>25 \mathrm{~kg} / \mathrm{m}^{2}$ \\
\hline 6 & High waist circumference & $\begin{array}{l}\text { If female: }>88 \mathrm{~cm} \\
\text { If male: }>102 \mathrm{~cm}\end{array}$ \\
\hline 7 & High visceral adipose tissue & VAT $>130 \mathrm{~cm}^{2}$ or VAT/TAT ratio $>0.5$ \\
\hline 8 & Sarcopenia or presarcopenia & Fat-free mass index $<-1 \mathrm{SD}$ \\
\hline 9 & Insulin resistance & Homeostasis Model Assessment - Insulin Resistance [41] > 2.8 \\
\hline 10 & High total cholesterol & $>200 \mathrm{mg} / \mathrm{dl}$ \\
\hline 11 & High low-density lipoprotein & $>100 \mathrm{mg} / \mathrm{dl}$ \\
\hline 12 & Low high-density lipoprotein & $<40 \mathrm{mg} / \mathrm{dl}$ \\
\hline 13 & High triglycerides & $>150 \mathrm{mg} / \mathrm{dl}$ \\
\hline 14 & High homocysteine & $\begin{array}{l}\text { If female: }>10 \mu \mathrm{mol} / \mathrm{l} \\
\text { If male: }>15 \mu \mathrm{mol} / \mathrm{l}\end{array}$ \\
\hline 15 & Abnormal white blood cell counts & $<4000$ cells $/ \mu \mathrm{l}$ \\
\hline 16 & Anemia & $\begin{array}{l}\text { If female: }<10 \mathrm{~g} / \mathrm{dl} \\
\text { If male: }<12 \mathrm{~g} / \mathrm{dl}\end{array}$ \\
\hline 17 & Hepatitis C coinfection & Positive \\
\hline 18 & Hepatitis B coinfection & Hepatitis B antigen positive \\
\hline 19 & Vitamin D insufficiency & $<30 \mathrm{ng} / \mathrm{ml}$ \\
\hline 20 & Polypharmacy & $>5$ drug classes (excluding antiretroviral therapy) \\
\hline 21 & Abnormal parathyroid hormone & $>60 \mathrm{pg} / \mathrm{ml}$ \\
\hline 22 & Elevated D-dimer & >Sample mean (358) \\
\hline 23 & Elevated C-reactive protein & $>0.7 \mathrm{mg} / \mathrm{l}$ \\
\hline 24 & Sedentary lifestyle & $<3 \mathrm{~h} /$ week physical activity \\
\hline 25 & Atherosclerosis & $\begin{array}{l}\text { Coronary artery calcium score }>100 \text { or intima media } \\
\text { thickness }>0.85 \mathrm{~mm}\end{array}$ \\
\hline 26 & Hyponatremia & $<125 \mathrm{mmol} / \mathrm{l}$ \\
\hline 27 & Proteinuria or albuminuria & $>5 \mathrm{mg} / \mathrm{mmol}$ \\
\hline 28 & Elevated aspartate transaminase & $>31 \mathrm{U} / \mathrm{l}$ \\
\hline 29 & Elevated alanine transaminase & $>31 \mathrm{U} / \mathrm{l}$ \\
\hline 30 & Abnormal alkaline phosphatase & $<38$ or $>126 \mathrm{U} / \mathrm{l}$ \\
\hline 31 & Elevated $\gamma$-glutamyl transphosphatase & $>55 \mathrm{U} / \mathrm{l}$ \\
\hline 32 & Low platelets & $<150$ billion/l \\
\hline 33 & Abnormal potassium & $<3.5$ or $>5.3 \mathrm{mEq} / \mathrm{l}$ \\
\hline 34 & Abnormal phosphorus & $<2.5$ or $>5.1 \mathrm{mg} / \mathrm{dl}$ \\
\hline 35 & Abnormal thyroid-stimulating hormone & $<0.27$ or $>4.2 \mathrm{mlU} / \mathrm{l}$ \\
\hline 36 & Elevated total bilirubin & $>1.10 \mathrm{mg} / \mathrm{dl}$ \\
\hline 37 & Unemployment & Self-report \\
\hline \multicolumn{3}{|c|}{ Comorbidities } \\
\hline 1 & Cardiovascular disease & Clinical diagnosis \\
\hline 2 & Hypertension & Measured blood pressure or on treatment \\
\hline 3 & Diabetes mellitus type II & Fasting glucose $>125 \mathrm{mg} / \mathrm{dl}$ or on treatment \\
\hline 4 & Chronic kidney disease & $\begin{array}{l}\text { Two estimated glomerular filtration rate measurements } \\
<60 \mathrm{ml} / \mathrm{min} / 1.73 \mathrm{~m}^{2}\end{array}$ \\
\hline 5 & Cirrhosis & FIB-4 score $>3.25$ \\
\hline 6 & Chronic obstructive pulmonary disease & Spirometry: FEV1/FVC ratio $<0.7$ \\
\hline 7 & Osteoporosis & $\begin{array}{l}\text { Dual-energy } X \text {-ray absorptiometry } T \text { or } Z \text { score }<-2.5 \text { or } \\
\text { fragility fracture }\end{array}$ \\
\hline 8 & Any cancer & Clinical diagnosis with biopsy confirmation \\
\hline \multicolumn{3}{|c|}{ HIV-related variables } \\
\hline 1 & Current $\mathrm{CD}^{+}{ }^{+}$cell count & $<500$ cells $/ \mu \mathrm{l}$ \\
\hline 2 & Nadir $\mathrm{CD}^{+}{ }^{+}$cell count & $<200$ cells/ $\mu$ l \\
\hline 3 & HIV viral load & $>40$ copies $/ \mathrm{ml}$ \\
\hline 4 & $\mathrm{CD}^{+} / \mathrm{CD}^{+}$cell ratio & $<1.0$ \\
\hline 5 & Duration of HIV infection & $>10$ years \\
\hline 6 & Pre-HAART start & Start of antiretroviral therapy before 1 January 1997 \\
\hline 7 & History of AIDS & History of CDC category C HIV disease [42] \\
\hline 8 & ART failure & History of viral load $>1000$ copes $/ \mathrm{ml}$ while on ART \\
\hline
\end{tabular}

ART, antiretroviral therapy; CDC, Centres for Disease Control; FEV1/FVC, forced expiratory volume in one second/forced vital capacity; FIB-4, fibrosis-4 score; FSH, follicle-stimulating hormone; LH, luteinizing hormone; SD, standard deviation; VAT/TAT, visceral adipose tissue/total adipose tissue. 
Table 2. Descriptive characteristics of the sample at first study visit.

\begin{tabular}{lc}
\hline Sample size, $n$ & 2722 \\
Age, mean \pm SD & $46 \pm 8$ \\
Women, $n(\%)$ & $867(32)$ \\
Current CD4 $4^{+}$cell count, mean \pm SD & $588 \pm 267$ \\
Nadir CD4 ${ }^{+}$cell count, mean \pm SD & $209 \pm 163$ \\
Undetectable HIV viral load, $n(\%)$ & $2577(93)$ \\
VACS index, mean \pm SD & $16 \pm 15$ \\
Pack-years smoking, mean \pm SD & $16 \pm 16$ \\
Injection drug use, $n(\%)$ & $730(27)$ \\
Multimorbidity ${ }^{\mathrm{a}}, n(\%)$ & $390(14)$ \\
Cardiovascular disease, $n(\%)$ & $95(4)$ \\
Hypertension, $n(\%)$ & $752(28)$ \\
Type 2 diabetes mellitus, $n(\%)$ & $254(9)$ \\
Chronic kidney disease, $n(\%)$ & $14(1)$ \\
Hepatic cirrhosis, $n(\%)$ & $150(6)$ \\
Chronic obstructive pulmonary disease, $n(\%)$ & $60(2)$ \\
Osteoporosis, $n(\%)$ & $368(14)$ \\
Cancer, $n(\%)$ & $26(1)$ \\
\hline
\end{tabular}

SD, standard deviation; VACS, Veterans Aging Cohort Study.

${ }^{a}$ Multimorbidity was defined as having two or more comorbidities out of hypertension, diabetes, chronic kidney disease, chronic obstructive pulmonary disease, osteoporosis, and cancer.

based on the assessment of a few, specific criteria. The present study is the first to explore frailty in relation to deficit accumulation among people aging with HIV. Our findings using the frailty index approach support those of the previous studies, including the associations of frailty with age, and with current $\mathrm{CD} 4^{+}$cell count $[40,44-49]$. The VACS index has been associated with multiple health outcomes in cross-sectional studies, including mortality, fragility fractures, and neurocognitive impairment $[34,50]$, as well as the frailty phenotype [16], and was correlated with the frailty index in our study. A recent study comparing a modified frailty phenotype scale and the VACS index within the VACS cohort found that both scales predicted hospitalization and mortality, and that the VACS index had better discriminatory ability [33]. We found that the frailty index and VACS index could similarly predict mortality. Otherwise few longitudinal

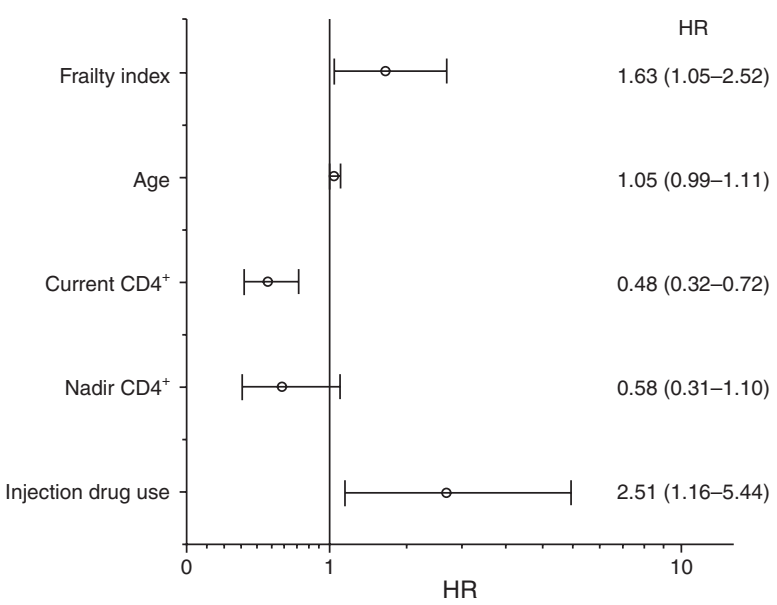

Fig. 1. Predictors of survival in multivariate analysis. Points represent adjusted HRs and whiskers 95\% confidence intervals. HR, hazard ratio.

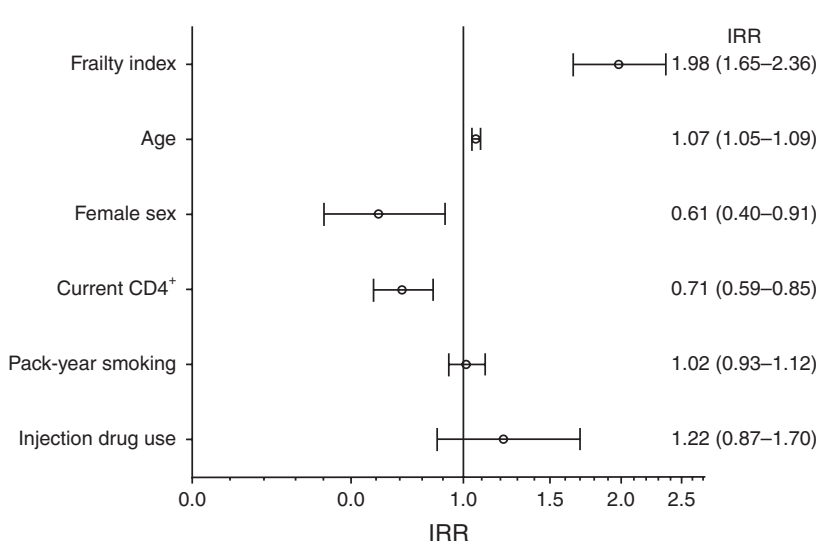

Fig. 2. Predictors of incident multimorbidity in multivariate analysis. Points represent adjusted IRRs and whiskers 95\% confidence intervals. IRR, incident rate ratio.

outcomes have been assessed in relation to frailty among people aging with HIV, especially among clinical cohorts [22]. The present study identified dose-response relationships of frailty with risk for mortality and for incident multimorbidity independent of HIV-related and behavioral factors. The predictive abilities of frailty assessment and changes in frailty over time should be explored further in HIV-related settings.

Many scales measure frailty, and just what scale is best among people with HIV has not been established. Previous reports of frailty in people with HIV have used rules-based approaches to frailty assessment, identifying phenotypic frailty [22] or using the VACS index [16,34]. However, the VACS index was developed specifically as a parsimonious prognostic tool, rather than to measure or characterize frailty. As such, its algorithm includes chronologic age. In this way, the VACS index differs from most frailty scales, which seek to quantify frailty independently from chronologic age [8]. The MHMC cohort does not currently capture the specific data necessary to calculate a frailty phenotype score, and VACS index scores were not available for $60 \%$ of included participants as these participants had at least one missing value. The infeasibility of calculating frailty phenotype and VACS index scores using the data routinely collected in the MHMC clinical setting illustrates that such rules-based approaches to defining frailty might be too specific, and not be appropriate in each individual case. Also, when fewer variables are used as in rules-based approaches, changes in the measurement approach of those few variables can significantly change estimates of frailty $[51,52]$.

Applying the frailty index approach enabled us to synthesize a large amount of routinely collected clinical information to assess health and frailty. Many experts will not doubt that health deficits are important, but some will be concerned by interactions between the items and wish for a list of fewer variables to be used. The inclusion of more items enables more pieces of information to 
Table 3. Area under receiver-operating characteristic curve for prediction of 2 and 5 -year mortality according to three different frailty indices and the Veterans Aging Cohort Study index.

\begin{tabular}{|c|c|c|c|}
\hline Frailty index & Description & AUC 2-year mortality $(95 \% \mathrm{Cl})$ & AUC 5-year mortality $(95 \% \mathrm{Cl})$ \\
\hline 37-item frailty index & - & $0.73(0.62-0.87)$ & $0.73(0.65-0.81)$ \\
\hline 45 -item frailty index & $\begin{array}{l}\text { 37-item frailty index }+8 \\
\text { comorbidity variables }\end{array}$ & $0.91(0.86-0.96)$ & $0.80(0.71-0.88)$ \\
\hline 53-item frailty index & $\begin{array}{l}\text { 37-item frailty index }+8 \\
\text { comorbidity variables }+8 \\
\text { HIV-related variables }\end{array}$ & $0.88(0.82-0.94)$ & $0.83(0.77-0.90)$ \\
\hline Veterans Aging Cohort Study Index & - & $0.92(0.89-0.95)$ & $0.81(0.68-0.95)$ \\
\hline
\end{tabular}

AUC, area under receiver-operating characteristic curve; $\mathrm{Cl}$, confidence interval.

contribute to the overall understanding of the level of frailty in an individual $[20,53]$. The accumulation of many small pieces of information is also well accepted in disciplines such as computational physics, decision science, and computer science $[54,55]$. In medicine, the deficit accumulation approach to frailty addresses a key lesson of aging that 'the problem of old age come as a package' [53]. The frailty index allows this package to be quantified, a useful step in getting to grips with the impact of aging with HIV.

We recognize that not all of these items will be collected in every HIV clinic, but most will, including waist circumference and BMI, information from regular blood work, the presence of polypharmacy, hepatitis coinfections, and HIV disease markers. Frailty indices can be composed of whatever information is already being collected, and these need not add extra cost. Variables can be answers to simple questions or clinical judgments (e.g. mobility impairment, memory, or mood complaints). In geriatric medicine, the use of comprehensive geriatric assessment enables the calculation of frailty indices across multiple health domains [56]. In our case, we selected these variables from among those the MHMC regularly collects. In other clinical settings, other frailty indices might incorporate different variables [57].

The frailty index in this study exhibited characteristics consistently demonstrated by frailty indices and other frailty scales in HIV-negative populations [20,25]. Frailty index scores had a normal distribution with a high mean score and a small, positive, nonlinear association with age that attenuated among the frailest participants (from $2 \%$ in the whole sample to zero in the frailest). These are all characteristic of frailty consistently observed among diverse clinical samples in HIV-negative populations $[10,20,25]$. Even though the mean frailty index score was high in this sample, the upper limit to frailty was not higher than expected (maximum around 0.7), which suggests that the index itself was not overestimating scores. Previous studies using the frailty index across many different settings suggest that this approach is stable and reliable when at least around 30 health variables are included $[14,20,25,27,30]$. When more variables are added, the characteristics and discriminative ability of the frailty index do not significantly change. This was also suggested by our data here. The frailty indices that incorporated more variables did not have a significantly better ability to discriminate mortality risk as estimated by the area under the ROC.

We found that frailty and current $\mathrm{CD} 4^{+}$cell count were each independently predictive of both survival and incident multimorbidity, and the addition of HIV-related variables into the frailty index did not significantly improve its ability to discriminate mortality risk. This suggests that frailty and current $\mathrm{CD} 4^{+}$cell count might be considered independent signals in assessing or quantifying vulnerability among people aging with HIV $[22,58]$. Although low $\mathrm{CD}^{+}$cell count is an important clinical sign, an increasing proportion of HIV-positive individuals on treatment are achieving immune recovery, and indeed most participants in this clinical cohort had $\mathrm{CD}^{+}$cell counts greater than $500 \mathrm{cells} / \mu \mathrm{l}$ and undetectable HIV viral load. Furthermore, IDU was a predictor of survival, suggesting that social vulnerability might play a role. The observational nature of this study did not allow us to demonstrate pathogenic mechanisms linking HIV disease severity, social vulnerability, frailty, and health outcomes. Understanding these links, including the development of frailty among people aging with high $\mathrm{CD}^{+}$cell counts, independent from immune deficiency, is motivating further work.

The practical utility of regular frailty assessment in HIV care has yet to be explored [22]. The ability to measure frailty holds potential value in terms of both policy and clinical care [8]. Identifying frailty and understanding how health status is likely to change can assist planning for services that might be required, and clinical frailty assessment can help to weigh the risks and benefits of interventions or predict risk of adverse outcomes [8]. Emerging information continues to suggest that frailty itself is treatable, and intervention is possible in preventing or delaying worsening frailty and functional decline [8]. Therefore, the frailty index could be investigated as a clinical tool and as an endpoint in intervention trials among people aging with HIV.

\section{Acknowledgements}

The authors would like to acknowledge all participants in the Modena HIV Metabolic Clinic cohort study, as well as 
Bruno Guidetti for technical assistance with database management.

In memoriam of Mrs Giuliana Rava.

This study is supported by the 'Co-morbidity in relation to AIDS’ grant agreement (305522), European Union Seventh Framework Programme.

All authors made substantial contributions to the final draft and approved the final version submitted for publication. T.D.B., S.K., J.F., C.Mussi, K.R., and G.G. conceived and designed the study. T.D.B. and S.Z. conducted the analysis. S.K., J.F., K.R., and G.G. supervised and assisted with analysis. T.D.B. and G.G. wrote the first draft. S.Z., C.S., F.C., A.M., A.S., M.M., C.Mussi, and C.Mussini contributed to data collection, cleaning, and database management, and provided critical intellectual input.

\section{Conflicts of interest}

G.G. has received research grants from Bristol-Myers Squibb, Gilead Sciences, and Jansen. He has received honoraria as speaker and/or advisor from Gilead Sciences, BMS, Merck, and Jansen. T.D.B. was supported by a Canadian Institutes of Health Research Summer Research Studentship. J.F. has received consulting fees from Theratechnologies, Inc., and has received payment for lectures from Viiv Canada, Gilead Canada, and Abbott Canada. K.R. is supported by the Dalhousie Medical Research Foundation through the Kathryn Allen Weldon Chain in Alzheimer Research. All other authors report no conflicts of interest.

\section{References}

1. Guaraldi G, Orlando G, Zona S, Menozzi M, Carli F, Garlassi E, et al. Premature age-related comorbidities among HIV-infected persons compared with the general population. Clin Infect Dis 2011; 53:1120-1126.

2. Deeks SG, Lewin SR, Havlir DV. The end of AIDS: HIV infection as a chronic disease. Lancet 2013; 382:1525-1533.

3. Schouten J, Wit FW, Stolte IG, Kootstra NA, van der Valk M, Geerlings SE, et al. Cross-sectional comparison of the prevalence of age-associated comorbidities and their risk factors between HIV-infected and uninfected individuals: The AGEhIV Cohort Study. Clin Infect Dis 2014; 59:1787-1797.

4. Althoff KN, McGinnis KA, Wyatt CM, Freiberg MS, Gilbert C, Oursler KK, et al. Comparison of risk and age at diagnosis of myocardial infarction, end-stage renal disease, and non-AIDSdefining cancer in HIV-Infected versus uninfected adults. Clin Infect Dis 2015; 60:627-638.

5. Guaraldi G, Silva AR, Stentarelli C. Multimorbidity and functional status assessment. Curr Opin HIV AIDS 2014; 9:386-397.

6. Justice AC, Braithwaite RS. Lessons learned from the first wave of aging with HIV. AIDS 2012; 26:S11-S18.

7. Negin J, Martiniuk A, Cumming RG, Naidoo N, PhaswanaMafuya $N$, Madurai $L$, et al. Prevalence of HIV and chronic comorbidities among older adults. AIDS 2012; 26:S55-S63.

8. Clegg A, Young J, Iliffe S, Rikkert MO, Rockwood K. Frailty in elderly people. Lancet 2013; 381:752-762.

9. Rockwood K, Song X, Mitnitski A. Changes in relative fitness and frailty across the adult lifespan: evidence from the Canadian National Population Health Survey. Can Med Assoc J 2011; 183:E487-E494.
10. Rockwood MR, MacDonald E, Sutton E, Rockwood K, Baron M, Pope J, et al. Frailty index to measure health status in people with systemic sclerosis. J Rheumatol 2014; 41:698-705.

11. Myers V, Broday DM, Steinberg DM, Yuval, Drory Y, Gerber Y. Exposure to particulate air pollution and long-term incidence of frailty after myocardial infarction. Ann Epidemiol 2013; 23:395-400.

12. Fried LP, Tangen $C M$, Walston J, Newman AB, Hirsch $C$, Gottdiener $\mathrm{J}$, et al. Frailty in older adults evidence for a phenotype. J Gerontol A Biol Sci Med Sci 2001; 56:M146M157.

13. Ãvila-Funes JA, Amieva $\mathrm{H}$, Barberger-Gateau P, Le Goff $M$, Raoux N, Ritchie K, et al. Cognitive impairment improves the predictive validity of the phenotype of frailty for adverse health outcomes: the Three-City Study. J Am Geriatr SoC 2009; 57:453-461.

14. Theou O, Brothers TD, Mitnitski A, Rockwood K. Operationalization of frailty using eight commonly used scales and comparison of their ability to predict all-cause mortality. I Am Geriatr Soc 2013; 61:1537-1551.

15. Theou O, Brothers TD, Peña FG, Mitnitski A, Rockwood K. Identifying common characteristics of frailty across seven scales. I Am Geriatr Soc 2014; 62:901-906.

16. Escota GV, Patel P, Brooks JT, Bush T, Conley L, Baker J, et al. The Veterans Aging Cohort Study Index is an effective tool to assess baseline frailty status in a contemporary cohort of HIVinfected persons. AlDS Res Hum Retroviruses 2015; 31:313317.

17. Mitnitski AB, Mogilner AJ, Rockwood K. Accumulation of deficits as a proxy measure of aging. Sci World / 2001; 1:323-336.

18. Kulminski AM, Ukraintseva SV, Kulminskaya IV, Arbeev KG, Land K, Yashin Al. Cumulative deficits better characterize susceptibility to death in elderly people than phenotypic frailty: lessons from the Cardiovascular Health Study. I Am Geriatr Soc 2008; 56:898-903.

19. Howlett SE, Rockwood MR, Mitnitski A, Rockwood K. Standard laboratory tests to identify older adults at increased risk of death. BMC Med 2014; 12:171.

20. Rockwood K, Mitnitski A. Frailty defined by deficit accumulation and geriatric medicine defined by frailty. Clin Geriatr Med 2011; 27:17-26.

21. Saum K-U, Dieffenbach AK, Müller H, Holleczek B, Hauer K, Brenner $\mathrm{H}$. Frailty prevalence and 10-year survival in community-dwelling older adults: results from the ESTHER cohort study. Eur J Epidemiol 2014; 29:171-179.

22. Brothers TD, Kirkland S, Guaraldi G, Falutz J, Theou O, Johnston $\mathrm{BL}$, et al. Frailty in people aging with human immunodeficiency virus (HIV) infection. J Infect Dis 2014; 210:11701179.

23. Brothers TD, Rockwood K. Biologic aging, frailty, and agerelated disease in chronic HIV infection. Curr Opin HIV AIDS 2014; 9:412-418.

24. Guaraldi G, Orlando G, Squillace N, De Santis G, Pedone A, Spaggiari A, et al. Multidisciplinary approach to the treatment of metabolic and morphologic alterations of HIV-related lipodystrophy. HIV Clin Trials 2006; 7:97-106.

25. Mitnitski A, Song X, Skoog I, Broe G, Cox JL, Grunfeld E, et al. Relative fitness and frailty of elderly men and women in developed countries and their relationship with mortality. J Am Geriatr Soc 2005; 53:2184-2189.

26. Pena F, Theou O, Wallace L, Brothers TD, Gill TM, Gahbauer EA, et al. Comparison of alternate scoring of variables on the performance of the frailty index. $B M C$ Geriatr 2014; $\mathbf{1 4 : 2 5 .}$

27. Rockwood K, Mitnitski A, Song X, Steen B, Skoog I. Long-term risks of death and institutionalization of elderly people in relation to deficit accumulation at age 70. I Am Geriatr SOC 2006; 54:975-979.

28. Theou $\mathrm{O}, \mathrm{O}^{\prime}$ Connell MDL, King-Kallimanis BL, O'Halloran AM, Rockwood K, Kenny RA. Measuring frailty using selfreport and test-based health measures. Age Ageing 2015; 44:471-477.

29. Wallace LMK, Theou O, Kirkland SA, Rockwood MRH, Davidson KW, Shimbo D, et al. Accumulation of non-traditional risk factors for coronary heart disease is associated with incident coronary heart disease hospitalization and death. PLOS One 2014; 9:e90475. 
30. Song X, Mitnitski A, Rockwood K. Age-related deficit accumulation and the risk of late-life dementia. Alzheimer Res Ther 2014; 6:54.

31. Streiner DL, Norman GR. Health measurement scales: a practical guide to their development and use. 4th ed. Oxford, UK: Oxford University Press; 2008.

32. Rockwood K, Rockwood MRH, Mitnitski A. Physiological redundancy in older adults in relation to the change with age in the slope of a frailty index. I Am Geriatr Soc 2010; 58:318-323.

33. Akgün KM, Tate JP, Crothers K, Crystal S, Leaf DA, Womack J, et al. An adapted frailty-related phenotype and the VACS index as predictors of hospitalization and mortality in HIV-infected and uninfected individuals. I Acquir Immune Defic Syndr 2014; 67:397-404.

34. Womack JA, Goulet JL, Gibert C, Brandt CA, Skanderson M, Gulanski $B$, et al. Physiologic frailty and fragility fracture in HIV-infected male veterans. Clin Infect Dis 2013; 56:14981504.

35. Tate JP, Justice AC, Hughes MD, Bonnet F, Reiss P, Mocroft A, et al. An internationally generalizable risk index for mortality after one year of antiretroviral therapy. AIDS 2013; 27:563572

36. Levey AS, Bosch JP, Lewis JB, Greene T, Rogers N, Roth D. A more accurate method to estimate glomerular filtration rate from serum creatinine: a new prediction equation. Ann Intern Med 1999; 130:461-470.

37. Sterling RK, Lissen E, Clumeck N, Sola R, Correa MC, Montaner $J$, et al. Development of a simple noninvasive index to predict significant fibrosis in patients with $\mathrm{HIV} / \mathrm{HCV}$ coinfection. Hepatology 2006; 43:1317-1325.

38. Guaraldi G, Cossarizza A, Franceschi C, Roverato A, Vaccher E, Tambussi $G$, et al. Life expectancy in the immune recovery era: the evolving scenario of the HIV epidemic in northern Italy. $)$ Acquir Immune Defic Syndr 2014; 65:175-181.

39. Palella FJ, Cole SR, Chmiel JS, Riddler SA, Visscher B, Dobs A, et al. Anthropometrics and examiner-reported body habitus abnormalities in the multicenter AIDS cohort study. Clin Infect Dis 2004; 38:903-907.

40. Ianas V, Berg E, Mohler MJ, Wendel C, Klotz SA. Antiretroviral therapy protects against frailty in HIV-1 infection. I Int AssoC Provid AIDS Care 2013; 12:62-66.

41. Matthews DR, Hosker JP, Rudenski AS, Naylor BA, Treacher DF, Turner RC. Homeostasis model assessment: insulin resistance and $\beta$-cell function from fasting plasma glucose and insulin concentrations in man. Diabetologia 1985; 28:412-419.

42. Castro KG, Ward JW, Slutsker L, Buehler JW, Jaffe HW, Berkelman RL, et al. 1993 revised classification system for HIV infection and expanded surveillance case definition for AIDS among adolescents and adults. Clin Infect Dis 1993; 17:802810.

43. Erlandson KM, Schrack JA, Jankowski CM, Brown TT, Campbell TB. Functional impairment, disability, and frailty in adults aging with HIV-infection. Curr HIV/AIDS Rep 2014; 11:279290.
44. Desquilbet L, Margolick JB, Fried LP, Phair JP, Jamieson BD, Holloway $M$, et al. Relationship between a frailty-related phenotype and progressive deterioration of the immune system in HIV-infected men. J Acquir Immune Defic Syndr 2009; 50:299-306.

45. Althoff KN, Jacobson LP, Cranston RD, Detels R, Phair JP, Li X, et al. Age, comorbidities, and AIDS predict a frailty phenotype in men who have sex with men. J Gerontol A Biol Sci Med SCi 2014; 69A:189-198.

46. Piggott DA, Muzaale AD, Mehta SH, Brown TT, Patel KV, Leng $S X$, et al. Frailty, HIV infection, and mortality in an aging cohort of injection drug users. PLOS One 2013; 8:e54910.

47. Pathai S, Gilbert C, Weiss HA, Cook C, Wood R, Bekker L-G, et al. Frailty in HIV-infected adults in South Africa. I Acquir Immune Defic Syndr 2013; 62:43-51.

48. Terzian AS, Holman S, Nathwani N, Robison E, Weber K, Young $M$, et al. Factors associated with preclinical disability and frailty among HIV-infected and HIV-uninfected women in the era of cART. J Womens Health 2009; 18:1965-1974.

49. Önen NF, Patel P, Baker J, Conley L, Brooks JT, Bush T, et al. Frailty and prefrailty in a contemporary cohort of HIV-infected adults. J Frailty Aging 2013; 3:158-165.

50. Marquine MJ, Umlauf A, Rooney AS, Fazeli PL, Gouaux BD, Woods SP, et al. The Veterans Aging Cohort Study index is associated with concurrent risk for neurocognitive impairment. J Acquir Immune Defic Syndr 2014; 65:190-197.

51. Saum K-U, Müller H, Stegmaier C, Hauer K, Raum E, Brenner H. Development and evaluation of a modification of the Fried frailty criteria using population-independent cutpoints. / Am Geriatr Soc 2012; 60:2110-2115.

52. Theou O, Cann L, Blodgett J, Wallace LM, Brothers TD, Rockwood K. Modifications to the frailty phenotype criteria: systematic review of the current literature and investigation of 262 frailty phenotypes in the Survey of Health, Ageing, and Retirement in Europe. Ageing Res Rev 2015; 21:78-94.

53. Fontana L, Kennedy BK, Longo VD, Seals D, Melov S. Medical research: treat ageing. Nature 2014; 511:405-407.

54. Shannon CE. Von Neumann's contributions to automata theory. Bull Amer Math Soc 1958; 64:123-129.

55. Dawes RM. The robust beauty of improper linear models in decision making. Am Psychol 1979; 34:571-582.

56. Krishnan M, Beck S, Havelock W, Eeles E, Hubbard RE, Johansen A. Predicting outcome after hip fracture: using a frailty index to integrate comprehensive geriatric assessment results. Age Ageing 2014; 43:122-126.

57. Drubbel I, de Wit NJ, Bleijenberg N, Eijkemans RJC, Schuurmans MJ, Numans ME. Prediction of adverse health outcomes in older people using a frailty index based on routine primary care data. J Gerontol A Biol Sci Med Sci 2013; 68:301-308.

58. Helleberg M, Kronborg G, Larsen CS, Pedersen G, Pedersen C, Obel N, et al. Poor CD4 response despite viral suppression is associated with increased non-AIDS-related mortality among HIV patients and their parents. AIDS 2013; 27:1021-1026. 